\title{
Application of In-situ Sonic Wave Test Method in the effect evaluation of grouting treatment in Weak Rock
}

\author{
Hongming Luo \\ State Key Laboratory of \\ Geomechanics and Geotechnical \\ Engineering, Engineering Research \\ Center of Rock-Soil Drilling and \\ Excavation and Protection,Ministry \\ of Education \\ Institute of Rock and Soil Mechanics, \\ Chinese Academy of Science, China \\ University of Geosciences \\ Wuhan, China \\ e-mail:hmluo@whrsm.ac.cn
}

\author{
Shanxiong Chen \\ State Key Laboratory of \\ Geomechanics and Geotechnical \\ Engineering \\ Institute of Rock and Soil Mechanics, \\ Chinese Academy of Science \\ Wuhan, China
}

\author{
Bo $\mathrm{Yu}$ \\ Guiyang Engineering Corporation \\ Limited, Power Construction \\ Corporation of China \\ Guiyang, China
}

\begin{abstract}
By using the borehole elastic modulus test and sound wave inspection for typical representative spots of a dam foundation, the deformation behavior parameters of grouted weak rock of workplace foundation are obtained, and the potential relationship between wave velocity VP and elastic modulus $E$ is derived. Then the quality of the rock is evaluated by the wave velocity. Comparative analysis shows that the consolidation grouting is better for the rock with poor engineering property under the natural condition, but for the rock with good mechanics strength characteristic, the improved effort is not very good. However, two test indicators are all satisfied with the analytical requirement. Therefore, this method is effective for grouting quality detection of rock.
\end{abstract}

Keywords-in-situ sonic wave test, weak rock, wave velocity, deformation modulus, rock mass quality, effect evaluation

\section{INTRODUCTION}

Elastic wave which is using in field dynamic tests is generated with pulse source. The acoustic parameters of Elastic wave propagation in rock mass will be changed, just likely wave velocity, vibration amplitude, frequency spectrum and so on, which is influenced by geological body such as lithology, structure, weathering degree, etc. The geological structure and physical and mechanical property of rock mass will be directly reflected by these changes, therefore, all kinds of physical and mechanical parameters using in constructing can be obtained by field dynamic test ${ }^{[1-3]}$.

Elastic wave which is using in field dynamic tests is generated with pulse source. The acoustic parameters of Elastic wave propagation in rock mass will be changed, just likely wave velocity, vibration amplitude, frequency spectrum and so on, which is influenced by geological body such as lithology, structure, weathering degree, etc. The geological structure and physical and mechanical property of rock mass will be directly reflected by these changes, therefore, all kinds of physical and mechanical parameters using in constructing can be obtained by field dynamic test ${ }^{[4]}$.

The foundation rock character is mainly argillaceous dolomite, breccia dolomite, marlite and mud stone of $\mathrm{T}_{1} \mathrm{yn}^{4}$ after excavating the workplace foundation of Guangzhao Hydropower Station of Beipanjiang River. The rock airslakes seriously and cracks are more developing. The karst is more developing in the contact zone between argillaceous dolomite and medium bedded limestone of $\mathrm{T}_{1} \mathrm{yn}^{3-2}$, and the P1 compress-crushed zone still goes through the middle of the factory. After the 40m excavation depth, on the surface it is mainly weathered rock, and there still is heavy weathered rock partly. The groundwater is active. The argillaceous dolomite that weathered seriously and breccia dolomite can fast emolliate and disintegrate when they contact the water. So the engineering nature is very bad and cannot satisfy the designing requirement. Soft rock mass of workplace foundation should be grouting reinforcement. Treatment effect of soft rock mass is inspected and evaluated by using the method for field dynamic test according to the corresponding relation between the acoustic wave of rock and deformation modulus, which is satisfied designing requirement.

\section{The PRINCIPLE FOR THE SONIC WAVE TESTING TECHNIQUE}

There are two kinds of in-situ test methods for rock strength, one is in-situ static load test and the other one is insitu dynamic test. Test result of the former method is visual and reliable, while the instrument is complex, bulkiness and destructive, large range test cannot be carried out. The latter method is simple, could be done in large range and the mechanics characteristics of rock mass can be reflected. The object of in-situ dynamic test is a certain range of rock which is in natural state, so the result can reflect real situation of the tested medium and is more meaningful in practical application. 
During the sonic wave test in rock, its velocity is not only influenced by lithology, structural face and development characteristics, weathering degree, but also related to stress state, water content condition and earth temperature, etc. In general, rock is the more compact and harder, and the wave velocity is much greater, conversely the wave velocity is the more least. When the lithology of rock mass is the same, the wave velocity is closely related to the characteristics of structural face. The wave velocity is found to increase with increasing stress under compressive stress, the amplitude attenuation is decreasing. Otherwise, the wave velocity is found to decrease with increasing stress under tensile stress, the amplitude attenuation is increasing. The water content of rock is much higher, the wave velocity is much greater, and the amplitude attenuation is much least. The influence of wave velocity on temperature is more complicate. Generally, when the rock mass is in positive temperature state, the wave velocity is found to increase with increasing temperature; it is contrary that the rock is in negative temperature state ${ }^{[5]}$.

The basic principal which is detected by sonic wave method that is high frequency elastic pulse wave is launched by emission source of ultrasonic pulse, the wave characteristics in rock mass propagation process is recorded by high precision receiving system. When discontinuous or damage interface exist in rock, wave impedance interface is formed in defects surface. With wave arriving the interface, the transmission and reflection of wave is produced, the energy of receiving transmitted wave is obviously lower. When serious defects such as fracture, structural plane and hole exist in rock, scattering and diffraction of wave is produced. The medium parameter in the scope of surveying area such as p-wave velocity $\mathrm{Vp}(\mathrm{m} / \mathrm{s})$ and compactness, etc, is obtained by the characteristics such as wave firstly arriving time, energy attenuation characteristics of wave, the change of frequency and the extent of distortion of waveform.

\section{THE CORRELATION RELATIONSHIP ANALYSIS ON DEFORMATION MODUlus AND WAVE VELOCITY OF WEAK ROCK}

In order to mechanical character of supporting course rock of workplace foundation, build the counter relation between the rock sonic wave and deformation modulus, provide pertinence geology parameter for settlement deformation calculation of workplace foundation and provide gist for using acoustic wave test in post foundation grouting management. The engineering geology workers go on sonic wave test to the main supporting course rock: argillaceous dolomite and breccia dolomite (with $\mathrm{P} 1$ compress-crushed zone) of $\mathrm{T}_{1} \mathrm{yn}^{4}$ according to integrating spot survey and indoor testing data and using physical prospecting after excavation to the foundation surface. We also go along corresponding borehole deformation modulus test in the $5 \mathrm{~m}$ depth of testing hole (it is influenced by the excavation and catchment) and make it respond to bore-hole wave test. The borehole wave test will be adopted by using RS-ST01C and $20 \mathrm{kHz}$ energy conversion, and the borehole in situ deformation modulus test will be adopted by using OYO-3030 lateral pressure testing instrument made in Japan. The instrument will record the pressure and strain value every time when adding to $5 \mathrm{~kg}$ in testing. Borehole deformation modulus and wave test results are shown in TABLE 1.

TABle 1 The Bore-Hole (Single-Hole) Deformation Modulus of WORKPLACE FOUNDATION AND WAVE TEST RESULT

\begin{tabular}{|c|c|c|c|c|}
\hline $\begin{array}{c}\text { Testing } \\
\text { borehole } \\
\text { number }\end{array}$ & $\begin{array}{l}\text { Pore } \\
\text { depth } \\
/ \mathrm{m}\end{array}$ & $\begin{array}{l}\text { Wave speed of } \\
\text { measuring point } \\
/ \mathrm{ms}^{-1}\end{array}$ & $\begin{array}{l}\text { Deformation } \\
\text { modulus } \\
\text { /GPa }\end{array}$ & Remark \\
\hline Zc1 & 3.4 & 4500 & 4.72 & $\begin{array}{l}\text { Limestone zone of } \\
\mathrm{T}_{1} \mathrm{yn}^{3-2}\end{array}$ \\
\hline Zc2 & 3.6 & 2400 & 0.46 & $\begin{array}{l}\text { Limestone zone } \\
\text { (erosion zone) of } \\
\mathrm{T}_{1} \mathrm{yn}^{3-2}\end{array}$ \\
\hline Zc3 & 3.8 & 2800 & 0.75 & $\begin{array}{l}\text { Argillaceous dolomite } \\
\text { zone of } \mathrm{T}_{1} \mathrm{yn}^{4}\end{array}$ \\
\hline Zc4 & 3.8 & 2400 & 0.38 & $\begin{array}{c}\text { Limestone zone } \\
\text { (erosion zone) of } \\
\mathrm{T}_{1} \mathrm{yn}^{3-2}\end{array}$ \\
\hline Zc5 & 3.0 & 2300 & 0.38 & $\begin{array}{l}\text { No.5 carst conduit } \\
\text { erosion zone }\end{array}$ \\
\hline Zc6 & 3.6 & 2100 & 0.26 & $\begin{array}{l}\text { P1 compress-crushed } \\
\text { zone }\end{array}$ \\
\hline $\mathrm{Zc7}$ & 4.1 & 2600 & 0.62 & $\begin{array}{l}\text { Argillaceous dolomite } \\
\text { zone of } \mathrm{T}_{1} \mathrm{yn}^{4}\end{array}$ \\
\hline Zc8 & 3.5 & 2700 & 0.76 & $\begin{array}{l}\text { Argillaceous dolomite } \\
\text { zone of } \mathrm{T}_{1} \mathrm{yn}^{4}\end{array}$ \\
\hline Zc9 & 3.7 & 2000 & 0.22 & $\begin{array}{c}\text { P1 compress-crushed } \\
\text { zone }\end{array}$ \\
\hline
\end{tabular}

According to the result of the foundation borehole wave text and the deformation modulus of the point text, the curve about the wave of breaking, weak stratum (including P1 compress-crushed zone) and the deformation modulus is showed in Fig.1. And the regression equation is as followed:

$$
\mathrm{Y}=5 \mathrm{E}-14 \mathrm{X}^{3.83}
$$

Where $\mathrm{Y}$ is deformation modulus, unit: $\mathrm{GPa}$, and $\mathrm{X}$ is borehole wave, unit: $\mathrm{m} / \mathrm{s}$.

The decision value of the above equation $r^{2}=0.9951$, which shows the relationship between $\mathrm{X}$ and $\mathrm{Y}$ is very good.

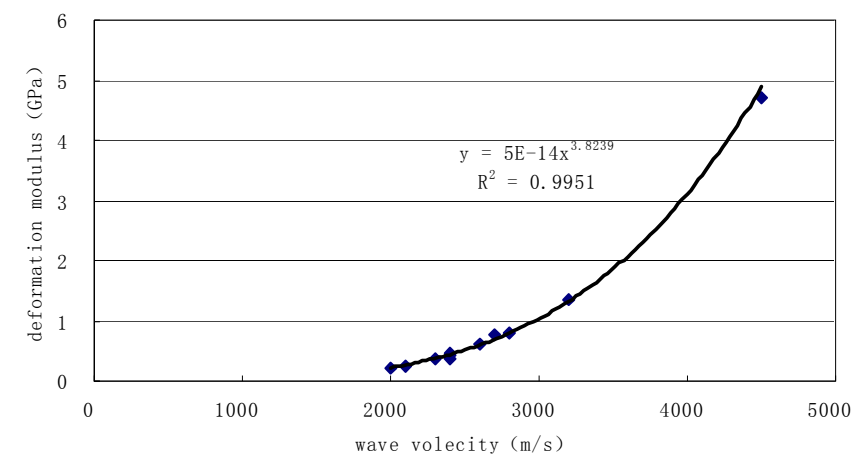

Fig. 1. the relationship curve between deformation modulus and drill hole wave of $\mathrm{T}_{1} \mathrm{yn}^{4}$ clayed dolomite layer in workplace foundation

\section{THE EFFECT EVAlUATION ON GROUTING TREATMENT IN WEAK ROCK OF POWERHOUSE FOUNDATION}

To test the improvement effort of the grouting to the strength of the rock mechanics, adopting the cross holes wave 
velocity and the single-hole sound wave ${ }^{[6]}$. In addition, testing the 11 couples of the cross holes wave velocity before grouting, 15 couples after the grouting and 1 hole of the single-hole sound wave before grouting, 5 holes after grouting.

As Fig.2 shows, comparing to the wave velocities between the $\mathrm{T}_{1} \mathrm{yn}^{4}$ medium clayey dolomite and breccia dolomite. The average wave velocity is $2746 \mathrm{~m} / \mathrm{s}$ before grouting, about $39 \%$ of these are more than $2800 \mathrm{~m} / \mathrm{s}$, and the average deformation modulus is $0.80 \mathrm{GPa}$. After grouting, the velocity of the sound wave increases $7 \%$, the deformation modulus increases $28 \%$. According to the results below, the strength of the rock mechanics is basically satisfied the design need before and after grouting, the average velocity is satisfied the design need of $2800 \mathrm{~m} / \mathrm{s}$. But near the northern part of the No.5 karst conduit and the P1 squeeze fracture zone, some partial test points cannot reach the need of the specified requirement. I presume that because the influences of the little karst holes which have partial development with filling clay. After the reinforcing grouting, the average velocity of the sonic wave is approximately $3039 \mathrm{~m} / \mathrm{s}$, about $96 \%$ of this is more than $2800 \mathrm{~m} / \mathrm{s}$, some points which cannot reach the need are mainly dribs and dabs on the upper of the floor. In according with the velocity of the sonic wave, the average deformation modulus is $1.2 \mathrm{GPa}$.

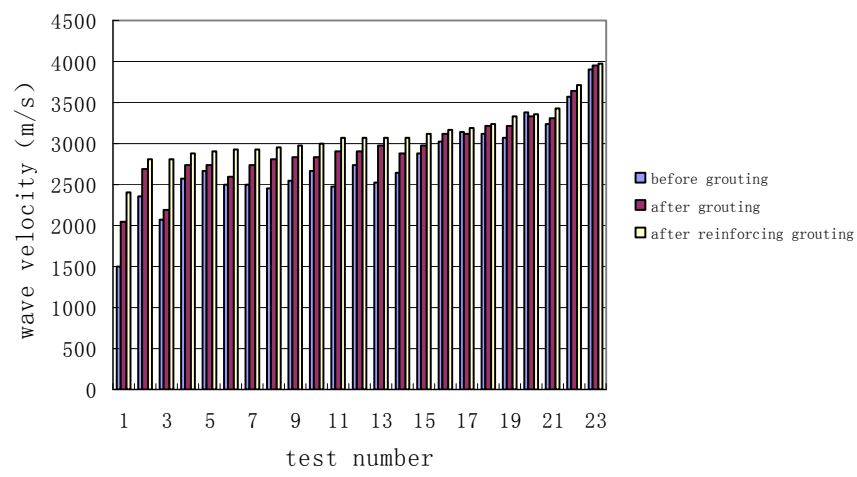

Fig. 2. the compared graph of treatment effort about the T1yn4 clayed dolomite layer

The Fig.3 shows that the treatment effect on grouting on the P1 squeeze fracture zone. The average sound wave is about $1950 \mathrm{~m} / \mathrm{s}$ before grouting, no testing points are more than $2800 \mathrm{~m} / \mathrm{s}$, and the average deformation modulus is $0.45 \mathrm{GPa}$. After reinforce grouting, the average velocity of the sound wave is $2835 \mathrm{~m} / \mathrm{s}$, about $92 \%$ of these are more than $2800 \mathrm{~m} / \mathrm{s}$, the average deformation modulus is about $0.82 \mathrm{GPa}$. The velocity of the sound wave in P1 squeeze fracture zone can basically reach the required need which is $2800 \mathrm{~m} / \mathrm{s}$ after reinforcing the grouting. The velocity of the sound wave increases $45 \%$, deformation modulus is as 4 times as before. But the results of the sound wave tests show that the fastest sound wave is $2917 \mathrm{~m} / \mathrm{s}$. It indicates that the mechanics strength is enhanced effectively by grouting in this fracture zone, but the upper limit is limited which conformity with the poor general characteristic.

The No.5 karst conduit mainly develops on the T1yn4 and T1yn3 division surface, because of the influence, on the south of the T1yn4, the karst and karst cavity develop well and the corrosion of the rock mass is crushing. Near the main conduit is the karst-collapse breccia. Before the grouting, the average velocity of the sound wave is $2617 \mathrm{~m} / \mathrm{s}$, about $17 \%$ of these are more than $2800 \mathrm{~m} / \mathrm{s}$, and the average deformation modulus is $0.68 \mathrm{G}$. After grouting treatment, the average velocity of the wave sound is $3059 \mathrm{~m} / \mathrm{s}$, about $69 \%$ of these are more than $2800 \mathrm{~m} / \mathrm{s}$, and the average deformation modulus is $1.22 \mathrm{GPa}$. The velocity increases $17 \%$ after grouting treatment; the deformation modulus increases $79 \%$. In a word, according to the influence of the karst, the castability of the rock is relative better; the strength of the rock has a high increase after grouting treatment.

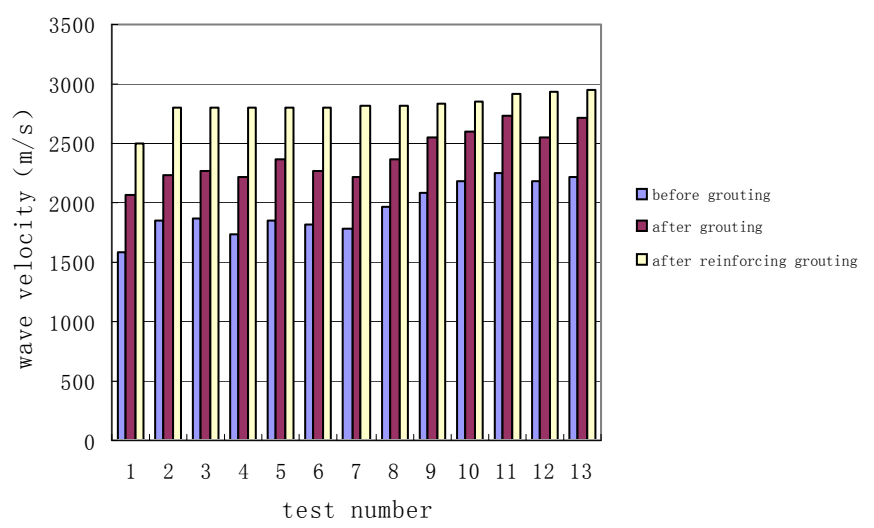

Fig. 3. the compared graph of the grouting treatment effort on the P1 squeeze fracture zone

\section{CONCLUSION}

From the aforementioned results and analyses, we can find several significant conclusions as follows:

In-situ dynamic tests always were carried out on the natural rock within a certain range. Therefore, the results can reflect the real situation of the medium and are more valuable for the practice. The engineering geological properties fore and after can be detected effectively by using the in situ dynamic tests method.

The research results show that there are good effects on the P1 fracture zone, No.5 karst conduit and T1Yn4 clayed dolomite layer after the grouting treatment, especially good for the rock with poor property under the natural condition. Adopting the reasonable construction technology, construction parameters and the consolidation grouting treatment to the depth holes, the mechanics strength of the foundation of the factory building is satisfied with the design need of the compressive stress.

According to the grouting treatment and the sonic wave test after adding the grouting treatment, the improved effect of the way of grouting treatment the reform effect for the rock with poor engineering property under the natural state is quite good. As for the rock with good engineering property, the improved effect is not very good. The improved effect of grouting treatment is related to comprehensive factors, such as the integrity of the rock and the property of grouting, etc. 


\section{ACKNOWLEDGMENTS}

This research is supported by the National Natural Science Foundation of China (Grant No.41402318) and Special Fund for Engineering Research Center of Rock-Soil Drilling \& Excavation and Protection of Ministry of Education, China University of Geosciences (Wuhan)(NO.CUG201306). The support is gratefully acknowledged. The author also thanks the anonymous referees whose comments helped to improve the work and the presentation of this paper.

\section{REFERENCES}

[1] Xi D.Y, Huang L.X., "Study on the acoustic characteristics of rock samples and parameters of in-situ measurement comparative”, Rock and Soil Mechanics. China, Vol.16, No.2, pp.52-56, 1995.
[2] Zhu H.C., "Sonic wave measuring and analysis of high rock slope", Chinese Journal of Rock Mechanics and Engineering. China, Vol.18, No.4, pp.378-381, 1999

[3] Ma R.T., "Sonic wave test method for rock mass and application on rock mass wave velocity sonic measurement of roadway surrounding rock", Railway Engineering. China, Vol.10, pp.37-40.

[4] Wang M.Y., Di Q.Y., Wang Y., et al., Exploration geophysics. Beijing, Earthquake publishing house , 2003.

[5] Zhao M.J., Wu D.L., "The ultrasonic identification of rock mass classification and rock mass strength prediction", Chinese Journal of Rock Mechanics and Engineering. China, Vol.19, No.1, pp.89-92, 2000.

[6] Quan H., "Detection of effect of high-pressure otary shotcreting grouting on river bed cover", Chinese Journal of Rock Mechanics and Engineering. China, Vol.25, No.2, pp.289-293, 2006. 